\title{
Universiteit
}

Leiden

The Netherlands

\section{The influence of semantic and phonological factors on syntactic decisions: An event-related brain potential study}

Schiller, N.O.; Muente, T.; Horemans, I.; Jansma, B.M.

\section{Citation}

Schiller, N. O., Muente, T., Horemans, I., \& Jansma, B. M. (2003). The influence of semantic and phonological factors on syntactic decisions: An event-related brain potential study. Psychophysiology, 40, 869-877. Retrieved from https://hdl.handle.net/1887/14160

Version: $\quad$ Not Applicable (or Unknown)

License: $\quad$ Leiden University Non-exclusive license

Downloaded from: https://hdl.handle.net/1887/14160

Note: To cite this publication please use the final published version (if applicable). 


\title{
The influence of semantic and phonological factors on syntactic decisions: An event-related brain potential study
}

\author{
NIELS O. SCHILLER, ${ }^{\mathrm{a}, \mathrm{b}}$ THOMAS F. MÜNTE, ${ }^{\mathrm{c}}$ IEMKE HOREMANS, ${ }^{\mathrm{a}}$ \\ AND BERNADETTE M. JANSMA ${ }^{\mathrm{a}}$ \\ ${ }^{\text {a}}$ Faculty of Psychology, Department of Cognitive Neuroscience, University of Maastricht, Maastricht, The Netherlands \\ ${ }^{\mathrm{b}}$ Max Planck Institute for Psycholinguistics, Nijmegen, The Netherlands \\ ${ }^{\mathrm{c} O t t o-v o n-G u e r i c k e-U n i v e r s i t a ̈ t, ~ M a g d e b u r g, ~ G e r m a n y ~}$
}

\begin{abstract}
During language production and comprehension, information about a word's syntactic properties is sometimes needed. While the decision about the grammatical gender of a word requires access to syntactic knowledge, it has also been hypothesized that semantic (i.e., biological gender) or phonological information (i.e., sound regularities) may influence this decision. Event-related potentials (ERPs) were measured while native speakers of German processed written words that were or were not semantically and/or phonologically marked for gender. Behavioral and ERP results showed that participants were faster in making a gender decision when words were semantically and/or phonologically gender marked than when this was not the case, although the phonological effects were less clear. In conclusion, our data provide evidence that even though participants performed a grammatical gender decision, this task can be influenced by semantic and phonological factors.
\end{abstract}

Descriptors: Psycholinguistics, Speech comprehension, ERPs, Grammatical gender, Semantic and phonological gender marking

One interesting question in psycholinguistics is the time course of information processing, that is, which processes precede or follow other processes and how long do the processes approximately take to be completed. In speech production, there is behavioral and ERP data available suggesting a specific time course of lexical access (Levelt, 2001). For instance, Schriefers, Meyer, and Levelt (1990) used the picture-word interference paradigm to investigate the relative time course of semantic and phonological information access and found that semantic knowledge is available earlier than phonological knowledge in speech production. Damian and Martin (1999) replicated this result. These and other data led Levelt to assume

Niels O. Schiller is supported by the Royal Dutch Academy of Arts and Sciences (KNAW). Furthermore, this work was supported by grants MU 1311/7-2 and MU 1311/9-1 from the Deutsche Forschungsgemeinschaft (DFG). The authors thank Jeroen Granzier (University of Maastricht) for his help in running the ERP experiment. The research reported in this article benefited from discussions at the Ninth Annual Meeting of the Cognitive Neuroscience Society in San Francisco (April 2002) and at the Symposium for Psycholinguistics in Barcelona (March 2003). Please note that B.M. Jansma published under her maiden name B.M. Schmitt until 2003.

Address reprint requests to: Niels O. Schiller, Faculty of Psychology, Department of Cognitive Neuroscience, Universiteit Maastricht, P. O. Box 616, 6200 MD Maastricht, The Netherlands. E-mail: n.schiller@, psychology.unimaas.nl. a specific time course in speech production (see overview in Levelt, Roelofs, \& Meyer, 1999). In his model, lexical access occurs in a number of steps starting at the conceptual level and going via semantic and syntactic encoding to phonological encoding. This time course has recently been substantiated by electrophysiological evidence. Schmitt and colleagues were the first to use the N200 during tacit picture naming, inspired by earlier work of Van Turennout and colleagues using the lateralized readiness potential or LRP (Van Turennout, Hagoort, \& Brown, 1997, 1998). In these studies, the subjects had to tacitly name pictures with motor responses (go/no-go, left/right hand) determined by semantic, syntactic, or phonological information. For example, Schmitt, Münte, and Kutas (2000) showed that the peak latency of the N200 was 89 ms earlier when the decision process leading to the effect could be made on the basis of semantic information than when it was made on the basis of phonological information (see also Rodriguez-Fornells, Schmitt, Kutas, \& Münte, 2002). This result replicated Van Turennout et al.'s (1997) earlier LRP findings. Furthermore, Schmitt, Schiltz, Zaake, Kutas, and Münte (2001) investigated the time course of conceptual and syntactic encoding during picture naming and found that conceptual information evoked an earlier N200 than syntactic information (by $73 \mathrm{~ms}$ ). Finally, Schmitt, Rodriguez-Fornells, Kutas, and Münte (2001) estimated the time from semantic to syntactic encoding to be approximately $80 \mathrm{~ms}$. Therefore, electrophysiological measurements have re- 
plicated earlier reaction time (RT) studies and extended those by providing fine-grained estimates of the temporal relationships between the processes involved in speech production.

In speech comprehension, Norris, McQueen, and Cutler (2000) made a strong case for the modularity of (spoken) word recognition. In their view, phonological/orthographic analysis precedes semantic and syntactic analysis (Cutler \& Clifton, 1999). Rodriguez-Fornells et al. (2002), using the latency of the N200 component of the event-related brain potential (ERP; see below) as a dependent measure, estimated that during auditory word processing, phonological information becomes available about $100 \mathrm{~ms}$ before semantic information. A further study using the N200 (Schmitt, Rodriguez-Fornells, et al., 2001) suggested that semantic information access precedes access to syntactic information by about $70 \mathrm{~ms}$, and Müller and Hagoort (2001), using the LRP, provided an estimate of between 70 and $100 \mathrm{~ms} .{ }^{1}$ This led us to assume that semantic knowledge is available earlier than syntactic knowledge during lexical access in speech comprehension.

Here, we assume that phonology/orthography, syntax, and semantics are independent levels of processing, which might have a sequential/cascading time course in comprehension. In this study, we use the N200 to test the independence of these three levels of processing. More specifically, we were interested in whether semantic and/or phonological information influences syntactic information processing in language comprehension (see also Deutsch, Bentin, \& Katz, 1999).

\section{The N200}

The N200 is a negative-going deflection of the ERP waveform. The overall functional significance of N200 is not yet clear (Eimer, 1993; Näätänen, 1982, 1992; Pfefferbaum, Ford, Weller, $\&$ Kopell, 1985), but there is consensus in the literature that the N200 is elicited when a potential response is withhold, as it is the case in go/no-go tasks. The N200 amplitude, therefore, is seen as a function of neuronal activity required for "response inhibition" in these tasks (Sasaki \& Gemba, 1993). Support for this assumption comes from studies that applied surface and depth (2-3 mm) recordings from the prefrontal cortex of monkeys (Sasaki, Gemba, \& Tsujimoto, 1989), as they performed a go/nogo task. The monkeys were trained on color discrimination, that is, they were required to push a button if a red light was switched on, and not to respond if a green light was switched on. No-go responses were associated with a cortical N200. Most important for the interpretation of the N200, however, is that when this cortical area was stimulated electrically during a go trial at the moment when the $\mathrm{N} 200$ would have its maximum, the go response was suppressed. The authors therefore suggested that the N200 is related to response inhibition (see also Geczy, Czigler, \& Balazs, 1999; Kopp, Rist, \& Mattler, 1996).

When a participant in a go/no-go paradigm is asked to respond to one class of stimuli (go trials), for example, by pressing a button, and not to respond to another class of stimuli (no-go trials), the ERP on no-go trials is characterized by a large negativity $(1-4 \mu \mathrm{V})$ compared to go trials between 100 and $300 \mathrm{~ms}$ after stimulus onset (N200). The N200 is especially

\footnotetext{
${ }^{1}$ In research on syntactic processing (i.e., parsing), it is debated whether or not syntactic analysis is independent of higher-level processes such as semantics. This debate is still open (see overview in Norris et al., 2000), but it mainly concerns sentence-level rather than word-level processes, which are the focus of this study.
}

marked over fronto-central electrode sides (Gemba \& Sasaki, 1989; Kok, 1986; Pfefferbaum et al., 1985; Sasaki, Gemba, Nambu, \& Matsuzaki, 1993; Simson, Vaughan, \& Ritter, 1977; Thorpe, Fize, \& Marlot, 1996). It has been suggested that the magnitude of the $\mathrm{N} 200$ is a function of the neural activity required for response inhibition (Jodo \& Kayama, 1992; Sasaki \& Gemba, 1993).

The presence of an N200 can be used as an indicator that the information necessary to determine whether or not to respond must have been available. One can manipulate the information on which a go/no-go decision is based and use the peak latency of the N200 (difference between go and no-go ERPs) as an upper estimate of when in time the specific information must have been encoded. As mentioned above, the N200 has been successfully applied in the area of language processing before.

\section{The Experimental Paradigm}

In the present study, participants were to make a binary decision, that is, classify words according to their grammatical gender (does the target have feminine [masculine] gender?). We aimed to use the peak latencies and amplitudes of the N200 to syntactic processing to determine whether semantic and/or phonological information influences syntactic processing during reading. Participants saw monomorphemic German nouns, one at a time, on a computer screen and were asked to classify each word according to its grammatical gender (masculine or feminine). Actually, participants' task was to determine the definite determiner of the target word: der for masculine and die for feminine targets. $^{2}$ Van Turennout et al. (1998) successfully applied a similar version of this syntactic decision task for Dutch. Dutch has two grammatical genders, that is, common and neuter (see overview in Schiller \& Caramazza, 2003). These two genders correspond to two determiners, that is, de and het. In Van Turennout et al.'s study, participants were required to judge by means of a button-press (i.e., go/no-go) or by selecting the response hand (i.e., left or right) whether the name of a given target picture had the determiner de or het. To solve this task, it is commonly assumed that speakers need to access grammatical information of the picture name (e.g., Heim, Opitz, \& Friederici, 2002). Moreover, Tucker, Lambert, and Rigault (1977) provided some evidence suggesting that (French) speakers construct a noun phrase of the type determiner+ noun to determine a noun's gender.

Grammatical gender is a lexical property of words, which is arbitrary for the most part. ${ }^{3}$ However, the grammatical gender of German words can be marked semantically (i.e., biological or natural gender, e.g., die Tante 'the aunt') and/or phonologically (i.e., phonological gender assignment rules identified by linguistic research, i.e., a word can have a "feminine" or a "masculine"

${ }^{2}$ Muller-Grass, Gonthier, Desrochers, and Campbell (2000) showed for French that the use of the determiners un versus une for gender decisions is about $200 \mathrm{~ms}$ faster than the use of the labels masculine and feminine. Their ERP data revealed significant peak amplitude differences between the two types of gender labels with more negative amplitudes for masculine/feminine than for un/une.

${ }^{3}$ German has three genders, namely feminine, masculine, and neuter. The distribution of the three genders in German is as follows: $38.76 \%$ of the words have masculine gender, $35.36 \%$ have feminine gender, and $25.88 \%$ are neuter (count corrected for frequency of occurrence and based on the CELEX database; Baayen, Piepenbrock, \& Gulikers, 1995). Because feminine and masculine gender occur approximately equally often in German, we decided to use these two genders in the experiment. 
phonology). The effectiveness of phonological gender assignment rules (see the Appendix for examples) has been proven experimentally (e.g., Köpcke \& Zubin, 1983; Mills, 1986; Schwichtenberg \& Schiller, in press).

It should be noted, however, that the semantic and especially the phonological rules are by no means without exception but rather probabilistic in nature. For example, in the semantic case, some German proper nouns in the diminutive form have clear male semantic gender, such as das Bübchen ('the little boy'), but have neuter grammatical gender. Another example would be das Weib ('the woman') with female semantic gender and neuter syntactic gender. In the phonological domain, there are even more "exceptions" from the rules. For example, the word der Rabe ('the raven') has a "feminine" phonology because it ends in a schwa, but nevertheless raven is masculine in German. Similarly, die Magd ('the maid') is "masculine" according to phonological rules (long vowel, high consonant-to-vowel ratio) but still it has feminine gender. ${ }^{4}$ Sometimes, there is a conflict of phonological rules favoring different genders, but there are no algorithms describing how individual rules interact with each other and how potential conflicts are resolved. That means comprehenders cannot solely rely on phonological or semantic information when they are required to make a gender decision about a word they see or hear. The phonological and semantic cues will only be able to prime a decision in one or the other direction, but the gender decision itself will have to be made by processing the syntactic feature information of a word to guarantee a correct response.

If the decision about the grammatical gender were based solely on syntactic information, semantic and/or phonological factors should not exert any influence on the syntactic decision. Strictly modular models would support such a position. However, if the syntactic decision can be influenced by semantic and/or phonological factors, we might use the N200 to investigate the time course of the relative contributions of each of these information components. The timing of the N200 (i.e., the difference between go and no-go responses) provides an upper limit about the moment in time when the respective information must be available for determining whether or not to respond. If semantic information about gender speeds up the syntactic decision, then the N200 should be earlier for the items with semantic gender compared to items without semantic gender information. If phonological cues can be used for gender determination, then the N200 should be visible earlier in the phonologically marked items compared to the phonologically unmarked items. Finally, if both semantic and phonological information speed up the syntactic decision, then this should be reflected by an additive effect, that is, the peak latency of the N200 for semantically and phonologically gender-marked items should be earliest.

\section{Method}

\section{Participants}

Fifteen native speakers of German (12 female, 3 male; mean age: 22.4 years) took part in the experiment. All participants were

${ }^{4}$ While the regularity in the semantic domain is certainly above $95 \%$ (i.e., words such as das Weib are rare exceptions), the phonological rules are clearly less regular: There are exceptions to almost every rule. However, exact numbers about the degree of regularity are not available.
Table 1. Experimental Conditions

\begin{tabular}{llll}
\hline \hline & & \multicolumn{2}{c}{ Semantic gender marking } \\
\cline { 3 - 4 } & & Marked (+) & Unmarked (-) \\
\hline $\begin{array}{l}\text { Phonological } \\
\text { gender } \\
\text { marking }\end{array}$ & Marked (+) & SEM +, & SEM - , \\
& & PHON + & PHON + \\
& Unmarked (- ) & SEM +, & SEM - , \\
& & PHON - & PHON - \\
\hline \hline
\end{tabular}

right-handed and had normal or corrected-to-normal vision. Participants were paid for their participation in the experiment.

\section{Materials}

Two hundred simple German monomorphemic words (100 feminine, 100 masculine) were used as targets. Half of them were semantically (biologically) marked for gender (e.g., der Bruder [male] $]_{\text {mas }}$ 'the brother'; die Braut[female] $]_{\text {fem }}$ 'the bride'; grammatical gender is indicated by a subscript, semantic gender, that is, sex, is indicated between square brackets), half of them

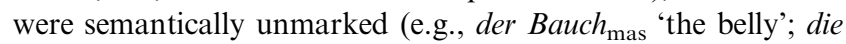
Brille $_{\text {fem }}$ 'the glasses'). Crossed with the semantic gender marking was the phonological make-up of the words. German nouns can either be phonologically marked for gender (e.g., der Knecht $[\text { male }]_{\text {mas }}$ 'the servant', i.e., words starting with $/ \mathrm{kn} /$ are generally masculine in German; die Hexe [female] $]_{\mathrm{fem}}$ 'the witch', i.e., words ending in schwa have a strong tendency to be feminine in German; Köpcke, 1982; Köpcke \& Zubin, 1984) or unmarked for gender (e.g., der Hirte[male] $]_{\text {mas }}$ 'the shepherd'; die Mutter [female $]_{\text {fem }}$ 'the mother'; the whole list of target words can be obtained from the first author). This resulted in four marking conditions (see Table 1). All targets were between 3 and 9 letters long (mean between 5.3 and 5.5 letters per target category) and the target categories had a mean frequency of occurrence between 16 and 30 per million as determined from the CELEX corpus (see Baayen et al., 1995), that is, all target word categories were of moderate frequency.

\section{Design}

Participants were tested on eight experimental blocks with the same stimuli. For each condition (go/no-go = masculine and go/ no-go $=$ feminine), participants received one practice block with 40 trials in the beginning of the experiment and four experimental blocks with 200 trials per block. The order of blocks was counterbalanced across participants. Sequence of words was randomized in every block and for every participant.

\section{Procedure}

Participants were tested individually while seated in a soundproof chamber in front of a computer screen. In every block, a syntactic decision was required, that is, did the visually presented word $^{5}$ have the masculine determiner der or the feminine determiner die? In half of the blocks participants were asked to

\footnotetext{
${ }^{5}$ Although phonological rules genuinely describe the sound of a word, they roughly also hold for the orthography (at least in an orthographically transparent language like German). Furthermore, the phonology of written words is activated very rapidly in visual word recognition (Perfetti \& Bell, 1991; Perfetti, Bell, \& Delaney, 1988). Therefore, whenever we speak about phonological (gender-marking) rules, we implicitly refer to rules about "form marking" in general to cover both phonological and orthographic gender marking.
} 
press the key when the determiner of the word was der (die) and withhold any response when the determiner of the word was die (der). In the other half, instructions were reversed and the same target words were shown again to get a response for every item (once as a go and once as a no-go response item). Each experimental block lasted about $10 \mathrm{~min}$. The entire experiment (including the placement of the electro cap) lasted about $2 \mathrm{hr}$.

A trial began with the presentation of a fixation cross (font size: $14 \mathrm{pt}$.) in the middle of a computer screen. The fixation cross was substituted by the word after a variable delay of between $1,800 \mathrm{~ms}$ and $2,300 \mathrm{~ms}$. We varied the period between fixation and stimuli presentation so that subjects would not built up a systematic expectancy in form of a contingent negative variation $(\mathrm{CNV})$. Each character of the target word covered approximately $0.3^{\circ}$ of visual angle. Target words were between three and nine letters long, subtending between $0.9^{\circ}$ and $2.7^{\circ}$ of visual angle. Words were presented in a white font on a black background. The word disappeared from the screen after $300 \mathrm{~ms}$. As soon as possible after the word appeared on the screen participants were required to give their response by pressing a button. RTs were registered automatically. The following trial began after an intertrial interval of $1,000 \mathrm{~ms}$.

Participants were instructed to rest their arms and hands on the elbow rest of the armchair and put the index finger of their right hand on the right button of a button-box in front of them. On go trials, participants were expected to respond by pressing the button as fast as possible. On no-go trials, no overt response was required. Participants were instructed not to speak, blink, or move their eyes while a word was on the screen.

\section{Apparatus and Recordings}

Button-press responses were measured from word onset with a time-out limit of 1,500 ms. Time-outs and wrong responses were considered as errors and excluded from the analyses. The electroencephalogram (EEG) was recorded from 29 scalp sites (extended version of the 10/20 system) using tin electrodes mounted in an electrode cap. Signals were digitized at $250 \mathrm{~Hz}$. Off-line analysis involved rereferencing of the scalp electrodes to the average activity of two electrodes placed on the left and right mastoid process. A bipolar montage of two electrodes placed below and above the left eye monitored eye blinks and vertical eye movements. A bipolar montage using two electrodes placed on the right and left external canthus monitored lateral eye movements. Eye movements were recorded for later off-line rejection of contaminated trials. Electrode impedance was kept below $5 \mathrm{k} \Omega$. Signals were amplified with a band-pass filter from 1 to $30 \mathrm{~Hz}$, and off-line band-pass filtered from 1 to $8 \mathrm{~Hz}$ for graphical display. Epochs of 1,000 ms [ $-100 \mathrm{~ms}$ to $+900 \mathrm{~ms}]$ were obtained, including a $100-\mathrm{ms}$ prestimulus baseline. The original number of trials per individual per condition was 200 . On average, $22.6 \%$ of the trials were excluded from further analysis (including ERP artifacts and incorrect responses). There were no differences in the number of rejections between conditions. The N200 was calculated per subject and condition. To isolate the N200, difference waves were computed by subtracting the ERP to the go trials of a particular condition from those to the no-go trials. In these difference waves, the latency and amplitude of the most negative peak in the 200-600-ms time window was determined. Peaks were rechecked visually. Because the N200 is generally largest for midline fronto-central electrodes, the analyses were restricted to $\mathrm{AFz}, \mathrm{Fz}, \mathrm{FCz}$, and $\mathrm{Cz}$ electrodes.

\section{Results}

\section{Button-Press Latencies}

Analyses of variance (ANOVAs) were run with target gender (masculine or feminine), semantic marking (marked vs. unmarked), and phonological marking (marked vs. unmarked) as independent variables. RTs faster than $300 \mathrm{~ms}$ or slower than $1,500 \mathrm{~ms}$ were excluded from the analysis. Less than $1 \%$ of the correct responses fell outside of these trimming criteria. Feminine targets $(660 \mathrm{~ms} ; S D=102)$ were responded to faster than masculine targets $(697 \mathrm{~ms} ; S D=107)$. This $37-\mathrm{ms}$ effect of target gender was significant, $F(1,14)=5.56, p<.05$. Semantic marking also yielded a significant effect: For the semantically (biologically) gender-marked items, the mean button press latency was $640 \mathrm{~ms}(S D=98)$, whereas for the semantically gender-unmarked items it was $696 \mathrm{~ms}(S D=105$; difference: $56 \mathrm{~ms}, F(1,14)=160.72, p<.001)$. Furthermore, for the phonologically gender-marked and -unmarked items, the mean buttonpress latencies were $657 \mathrm{~ms}(S D=104)$ and $679 \mathrm{~ms}(S D=106)$, respectively. This $22-\mathrm{ms}$ difference, albeit smaller than the semantic gender-marking effect, was reliable, $F(1,14)=26.28$, $p<.001$. There was no interaction between semantic and phonological gender marking, $F(1,14)<1$. However, target gender interacted with phonological marking, $F(1,14)=10.66$, $p<.01$. This interaction was due to the fact that the phonological gender-marking effect was more pronounced for masculine targets $(28 \mathrm{~ms})$ than for feminine targets $(15 \mathrm{~ms})$. All other interactions were nonsignificant.

\section{Error Rates}

The button-press latencies are generally supported by the error analyses, excluding a speed-accuracy trade-off. Altogether, participants made $6.5 \%$ errors. There was no effect of target gender, $F(1,14)=1.27$, n.s. However, gender marking yielded effects: In the semantically gender-marked condition, fewer errors $(5.1 \% ; S D=10.1)$ were made than in the semantically gender-unmarked condition $(9.8 \% ; S D=10.2, F(1,14)=32.61$, $p<.001)$. Similarly, in the phonologically gender-marked condition, participants made fewer errors $(6.6 \% ; S D=10.0)$ than in the phonologically gender-unmarked condition $(8.3 \%$; $S D=10.8, F(1,14)=7.29, p<.05)$. The two effects of semantic marking and phonological marking are additive, indicated by the lack of an interaction, $F(1,14)<1$. However, there was an interaction between target gender and semantic marking, $F(1,14)=4.83, p<.05$, due to the fact that semantic marking yielded fewer errors for masculine targets $(2.7 \% ; S D=3.5)$ than for feminine targets $(7.4 \% ; S D=13.5)$. None of the other interactions approached significance.

\section{N200 Analysis}

The N200 analysis is based on the assumption that increased negativity for no-go trials relative to go trials reflects the moment in time by which the relevant information necessary to withhold a button-press response must have been encoded. The time it takes to encode the relevant information might, therefore, be seen in the peak latencies and the peak amplitudes of the N200. There was no difference (based on serial paired $t$ tests) between the ERP difference waveforms for masculine and feminine targets. Therefore, data for both target genders were collapsed for subsequent analyses. ERP signals were averaged per participant and condition. Grand average ERPs were obtained separately 


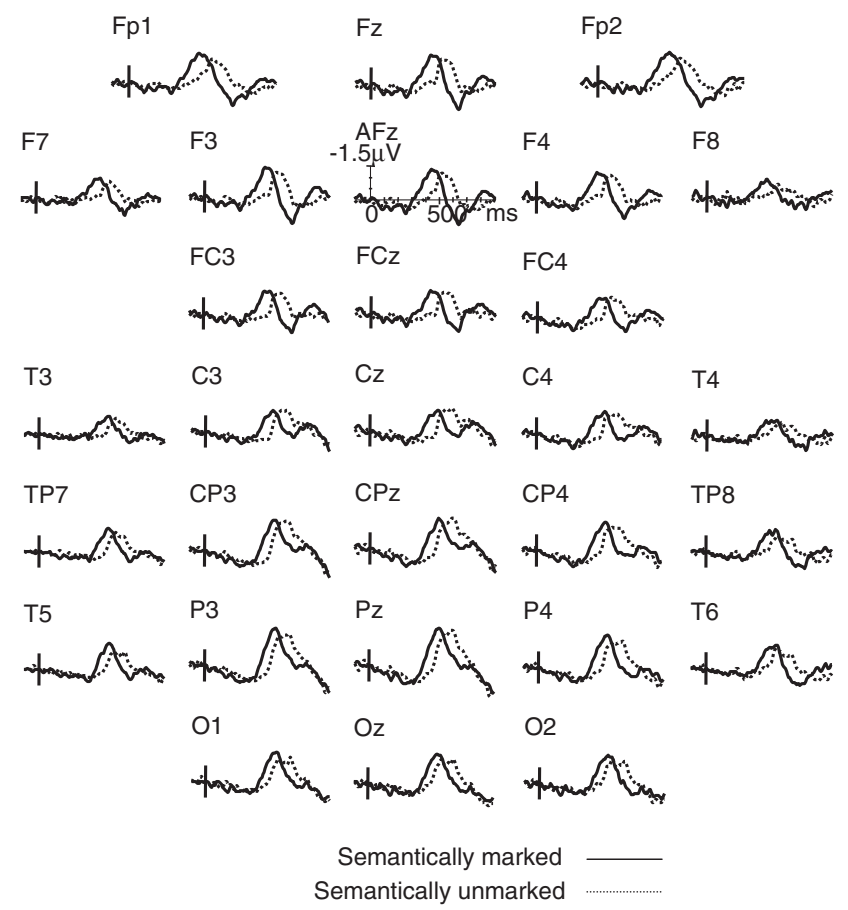

Figure 1. Grand average difference ERP (no-go minus go) waveforms for semantically marked and unmarked conditions. Solid lines show semantically gender-marked conditions; semantically gender-unmarked conditions are shown by dotted lines. Displayed are data from 15 participants for all electrode sites. Negative voltage is plotted up in this and all subsequent figures.

for the semantically and phonologically gender-(un)marked conditions.

ERP difference waveforms (no-go minus go) were calculated per participant and condition. Figures 1 and 2 display grand average difference ERP waveforms for semantically marked and unmarked conditions (pooled across phonological gender marking) and phonologically marked and unmarked conditions (pooled across semantic gender marking), respectively. As can be seen, a widely distributed N200 is visible in all conditions. Furthermore, there is a shift in time of the N200 effect visible for the semantic condition (Figure 1), but not for the phonological condition. Because the N200 is generally strongest across frontal sites, we will restrict all further analyses to four midline electrodes (i.e., $\mathrm{AFz}, \mathrm{Fz}, \mathrm{FCz}$, and $\mathrm{Cz}$ ).

Figure 3 shows grand average ERP waveforms for each condition for 15 participants at midline sites (AFz, Fz, FCz, and $\mathrm{Cz}$ ). All four conditions showed an N200, with no-go responses being more negative than go responses. Also, grand average difference waves were calculated (see Figure 4; left and middle panels). As can be seen in Figure 4 (right panel), the peak latency of the difference waves is determined by semantic gender marking alone with phonological gender marking not playing any role.

The statistical comparison of the ERP difference waveforms for each condition at four midline electrodes ( $\mathrm{AFz}, \mathrm{Fz}, \mathrm{FCz}$, and $\mathrm{Cz}$ ) supported the above description of the results based on visual inspection of the waveforms. For each participant, peak latencies and peak amplitudes (voltage value at the peak) of the N200 were measured at each of the four electrode sites for correct trials (200 trials minus errors). For the peak latencies as well as peak amplitudes, ANOVAs were carried out with semantic marking,

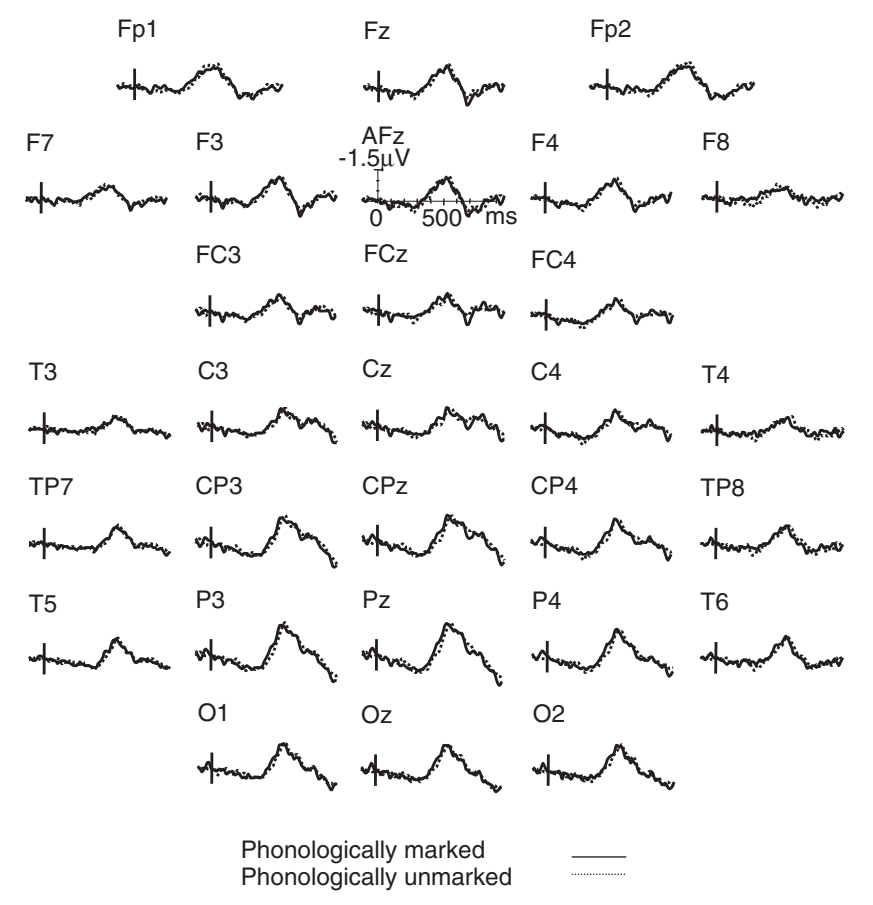

Figure 2. Grand average difference ERP (no-go minus go) waveforms for phonologically marked and unmarked conditions. Solid lines show phonologically gender-marked conditions; phonologically genderunmarked conditions are shown by dotted lines. Displayed are data from 15 participants for all electrode sites.

phonological marking, and electrode site ( $\mathrm{AFz}, \mathrm{Fz}, \mathrm{FCz}$, and $\mathrm{Cz}$ ) as factors.

The main effect of semantic markedness $(84 \mathrm{~ms})$ was significant, but not the main effect of phonological markedness $(8 \mathrm{~ms})$. The mean peak latency difference (across the four electrode sites) between the semantically marked $(461 \mathrm{~ms})$ and the semantically unmarked condition $(545 \mathrm{~ms}$ ) was $84 \mathrm{~ms}$ (see also Figure 4). This effect was highly significant, $F(1,14)=31.92$, $p<.001$. It shows that a syntactic decision (der vs. die) can be influenced by semantic information, in agreement with our working model. However, phonological gender marking did not influence the N200 latencies: The phonologically gender-marked $(477 \mathrm{~ms})$ and the phonologically gender-unmarked conditions $(485 \mathrm{~ms})$ were statistically indistinguishable. Neither electrode site, $F(3,42)=1.17$, n.s., nor the interaction between electrode site and semantic or phonological marking, $F(3,42)<1$, were significant.

The peak amplitudes did not show an effect of semantic marking, $F(1,14)=2.43$, n.s. (see also Figure 4 ). The mean peak amplitude difference (across the four electrode sites) between the semantically marked $(-2.68 \mu \mathrm{V})$ and the semantically unmarked condition $(-2.43 \mu \mathrm{V})$ was only $0.25 \mu \mathrm{V}$. Phonological marking did not reveal an effect either, $F(1,14)<1$, because the mean peak amplitude difference (across the four electrode sites) between the phonologically marked $(-2.91 \mu \mathrm{V})$ and the phonologically unmarked conditions $(-2.81 \mu \mathrm{V})$ was minimal $(0.10 \mu \mathrm{V})$. However, the interaction between semantic marking and phonological marking was significant, $F(1,14)=7.99$, $p<.05$. This interaction reflected the fact that the semantically and phonologically gender-marked condition differed significantly from the semantically gender-unmarked, but phonologically gender-marked condition, $F(1,14)=20.14, p<.01$. 


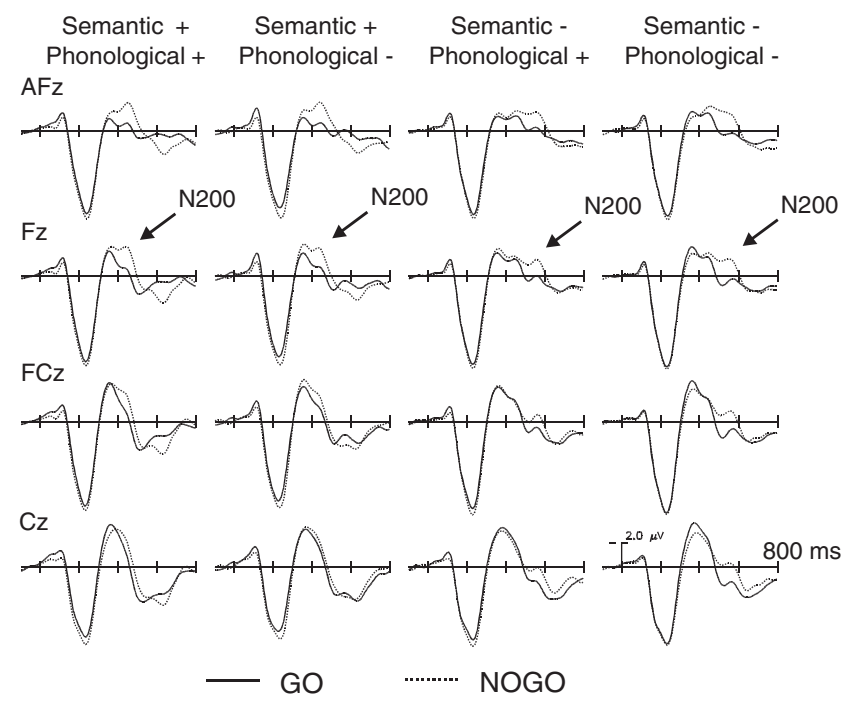

Figure 3. Grand average ERP waveforms for go and no-go trials for semantic and phonological gender-marking conditions. The ERPs were time locked to visual word onset. All four conditions are associated with an N200. Displayed are data from 15 participants (200 trials per participant per condition minus rejected trials) over four midline electrode sites ( $\mathrm{AFz}, \mathrm{Fz}, \mathrm{FCz}$, and $\mathrm{Cz}$ ).
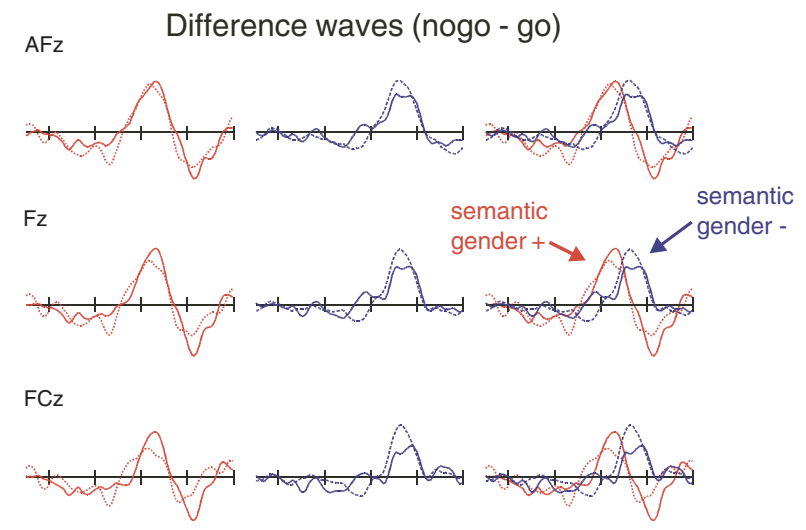

$\mathrm{Cz}$

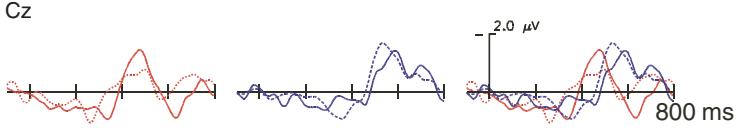

- Semantic Gender + Phonological Gender +

....... Semantic Gender + Phonological Gender -

- Semantic Gender - Phonological Gender +

...... Semantic Gender - Phonological Gender -

Figure 4. Grand average difference ERP waveforms for semantic and phonological gender-marking conditions. Semantically gender-marked conditions are shown in the left panel; semantically gender-unmarked conditions are shown in the middle panel. All four difference-waveforms are overlaid in the right panel. Displayed are data from 15 participants over four midline electrode sites.

Furthermore, the semantically gender-marked, but phonologically gender-unmarked condition differed from the semantically gender-unmarked, but phonologically gender-marked condition, $F(1,14)=14.44, p<.01$. The effect of electrode site was also significant, $F(3,12)=7.08, p<.01$. None of the interactions with electrode site were significant.

\section{Discussion}

The behavioral data clearly showed effects of both semantic and phonological factors on grammatical gender decisions: When semantic and/or phonological gender marking is available, the reader uses this information, resulting in faster RTs for the syntactic decision. This means that a syntactic decision can be influenced by either semantic or phonological information. But, since semantic and phonological marking did not interact, they are additive factors. This would support a model of word processing in which the individual semantic and phonological components function independently of each other and cannot influence each other.

We also found that the N200 varied in latency as a function of the condition in which the go/no-go decision was made. The N200 peak latency results suggest that in this experiment semantic gender information helps to access syntactic gender information. However, when no semantic information about the gender is provided, phonological information does not speed up syntactic information availability compared to phonologically unmarked items. This means that syntactic gender access in reading might not be influenced by phonological information, but this contrasts with the behavioral data (see above). It may be possible, however, that our ERP measurements were not sensitive enough to detect a small latency difference $(22 \mathrm{~ms})$, which may actually be in our data (due to a high signal-to-noise ratio).

However, an interaction between semantically and phonologically (un)marked items was observed in terms of the N200 peak amplitudes. In the semantically gender-marked cases, the phonologically gender-marked condition yielded higher amplitudes than the phonologically gender-unmarked condition. ${ }^{6}$ In contrast, for the semantically gender-unmarked conditions, the phonological amplitude effect was reversed. Though we obtained an interactive effect of phonological and semantic gender marking on N200 amplitude, we refrain from discussing this effect any further. While amplitude effects on the N200 have been reported in several instances (e.g., Falkenstein, Hoormann, \& Hohnsbein, 1999; Rodriguez-Fornells et al., 2002), the precise determinants of the amplitude variability are not yet known. Nevertheless, the interaction observed in the amplitudes may support an interactive processing model in which the individual components (semantic, phonological, etc.) can influence the syntactic decision and each other.

The perspective that the grammatical decoder takes into account not only syntactic, but also semantic information is reminiscent of the maximal input view in speech production put forward by Vigliocco and Franck (1999, 2001). In a sentence completion task, they demonstrated the influence of biological gender on grammatical agreement in Italian and French adjective noun phrases (Vigliocco \& Franck, 1999). Specifically, they found fewer agreement errors between the gender-marked adjective and the head noun when the noun had biological gender than when it had only grammatical gender. According to Vigliocco and Franck (1999; see also Vigliocco \& Franck, 2001) these results support a maximal input view according to which

\footnotetext{
${ }^{6}$ One potential explanation for the relatively low amplitude of the semantically marked, phonologically unmarked condition is that it contained words like Hirte [male] ('shepherd') or Magd [female] ('maid'), which are semantically male or female, but have a "feminine" or "masculine" phonology, respectively. That is, the set of phonologically unmarked items contained words that basically prime the opposite gender. This was not the case for the phonologically marked item set.
} 
nonsyntactic information, such as conceptual information about the biological gender on the noun referent, is taken into account during grammatical encoding, such as computing gender agreement between the subject and a predicative adjective. Our data might suggest that this maximal input view may also be applied to speech comprehension in the following way: The grammatical decoder not only takes grammatical/syntactic information into account, but also conceptual information, such as biological gender (as shown in the data reported above), when the grammatical gender of a noun has to be determined.

Alternatively, it may be possible that participants did not make a syntactic decision in all cases but rather employed a semantic strategy-because there were no semantic gender exceptions in our materials. In general, the semantic (biological) gender of German words almost exclusively-though not necessarily - corresponds to its grammatical gender. For instance, words that are biologically marked for feminine (masculine) natural gender (all words referring to human beings or animals with feminine [masculine] sex, e.g., die Frau 'the woman' or der Kater 'the tom cat'), generally also have feminine (masculine) grammatical gender (exceptions would be, e.g., das Weib, 'the woman' [with pejorative connotation] and das Mädchen 'the girl,' which both have neuter gender in German). Since the choice of the determiner (der or die) is entirely specified by the grammatical gender of a word in German (unlike Italian), it is conceivable that participants made the syntactic decision based on semantic information retrieval only, without bothering to retrieve the grammatical gender of the corresponding word form. Especially if semantic processing precedes syntactic processing in comprehension, such a scenario would make sense, although it may not have been the case. This could potentially explain the faster RTs and lower error rates in the behavioral data and the earlier peak latencies in the ERPs for the semantically gender-marked targets. Granting the assumption that we measured a semantic gender decision but not a syntactic gender decision in the semantically marked targets, the observed peak latency difference of $84 \mathrm{~ms}$ between semantically (biologically) gender-marked and gender-unmarked items confirms the previous studies, which found that semantics precedes syntactic information access by between 70 and $100 \mathrm{~ms}$ (Müller \& Hagoort, 2001; Schmitt, Rodriguez-Fornells, et al., 2001). However, the interaction between semantic and phonological marking in the ERP peak amplitudes remains unexplained by this strategic account.
A second alternative would be that ERP and RT tap into different information-processing stages. If we assume that ERPs are measuring early effects in target word processing, the ERP peak latency effect found for semantic marking might reflect either an early semantic or syntactic processing for gender retrieval. RTs might include later processing stages, such as orthographic and/or phonological self-monitoring of the target, and this might have had an effect on RTs and error rates. There is behavioral as well as initial psychophysiological evidence that speakers are able to internally self-monitor different types of phonological information such as segments (Schiller, 2002; Wheeldon \& Levelt, 1995; Wheeldon \& Morgan, 2002), syllables and syllable boundaries (Jansma \& Schiller, 2003; Morgan \& Wheeldon, 2003; Wheeldon \& Levelt, 1995), as well as lexical stress (Schiller, Bles, \& Jansma, in press; Schiller, Jansma, Peters, $\&$ Levelt, 2002). Maybe this internal phonological loop facilitates the gender decision at a later stage such as that the influence is no longer visible in the ERP but shows up as a reliable effect in the RTs. This could potentially account for the difference between ERP peak latencies and RTs/error rates.

By applying high-temporal resolution ERP to word reading in a simple go/no-go N200 paradigm, we observed clear timecourse information of semantic and phonological processing. The ERP waves of go and no-go responses diverge from each other in the time window of 450 to $550 \mathrm{~ms}$, especially at frontal sites. The latency of the N200 peak is contingent on whether or not words were semantically marked for gender. We were thus able to estimate on-line the influences of semantic and phonological processing on syntactic gender decision during visual word comprehension.

In summary, we employed the N200 (related to response inhibition) to monitor on-line word comprehension. Specifically, we investigated whether semantic and/or phonological gender information can influence syntactic gender decisions. Brain waves showed an effect for semantic but not for phonological gender marking on the decision. The reaction times, however, showed an effect of both semantic and phonological gender information on the task. Syntactic gender decision was speeded up by semantic and phonological gender information (measured by faster RTs). Taken together, we suggest that RT and ERP effects together indicate an influence of semantic as well as phonological information on the syntactic information access.

\section{REFERENCES}

Baayen, R. H., Piepenbrock, R., \& Gulikers, L. (1995). The CELEX lexical database (CD-ROM). Philadelphia: Linguistic Data Consortium, University of Pennsylvania.

Cutler, A., \& Clifton, C. (1999). Comprehending spoken language: A blueprint of the listener. In C. M. Brown \& P. Hagoort (Eds.), The neurocognition of language (pp. 132-166). Oxford: Oxford University Press.

Damian, M. F., \& Martin, R. C. (1999). Semantic and phonological codes interact in single word production. Journal of Experimental Psychology: Learning, Memory, and Cognition, 25, 345-361.

Deutsch, A., Bentin, S., \& Katz, L. (1999). Semantic influence on processing gender agreement: Evidence from Hebrew. Journal of Psycholinguistic Research, 28, 515-535.

Eimer, M. (1993). Effects of attention and stimulus probability on ERPs in a go/nogo task. Biological Psychology, 35, 123-138.
Falkenstein, M., Hoormann, J., \& Hohnsbein, J. (1999). ERP components in go/nogo tasks and their relation to inhibition. Acta Psychologica, 101, 267-291.

Geczy, I., Czigler, I., \& Balazs, L. (1999). Effects of cue information on response production and inhibition measured by event-related potentials. Acta Physiologica Hungarica, 86, 37-44.

Gemba, H., \& Sasaki, K. (1989). Potential related to no-go reaction of go/no-go hand movement task with color discrimination in human. Neuroscience Letters, 101, 262-268.

Heim, S., Opitz, B., \& Friederici, A. D. (2002). Broca's area in the human brain is involved in the selection of grammatical gender for language production: Evidence from event-related functional magnetic resonance imaging. Neuroscience Letters, 328, 101-104.

Jansma, B. M., \& Schiller, N. O. (2003). Monitoring syllable boundaries during speech production. Manuscript submitted for publication. 
Jodo, E., \& Kayama, Y. (1992). Relation of a negative ERP component to response inhibition in a go/nogo task. Electroencephalography and Clinical Neurophysiology, 82, 477-482.

Kok, A. (1986). Effects of degradation of visual stimuli on components of the event-related potential (ERP) in go/nogo reaction tasks. Biological Psychology, 23, 21-38.

Köpcke, K.-M. (1982). Untersuchung zum Genussystem der deutschen Gegenwartssprache [Investigation of the gender system in contemporary German]. Tübingen: Niemeyer.

Köpcke, K.-M., \& Zubin, D. (1983). Die kognitive Organisation der Genuszuweisung zu den einsilbigen Nomen der deutschen Gegenwartssprache [The cognitive organization of gender assignment on monosyllabic nouns in contemporary German]. Zeitschrift für germanistische Linguistik, 11, 166-182.

Köpcke, K.-M., \& Zubin, D. (1984). Sechs Prinzipien für die Genuszuweisung im Deutschen: Ein Beitrag zur natürlichen Klassifikation [Six principles of gender assignment in German: A contribution to natural classification]. Linguistische Berichte, 93, 26-50.

Kopp, B., Rist, F., \& Mattler, U. (1996). N200 in the flanker task as a neurobehavioral tool for investigating executive control. Psychophysiology, 33, 282-294.

Levelt, W. J. M. (2001). Spoken word production: A theory of lexical access. Proceedings of the National Academy of Sciences, USA, 98, 13464-13471.

Levelt, W. J. M., Roelofs, A., \& Meyer, A. S. (1999). A theory of lexical access in speech production. Behavioral and Brain Sciences, 22, 1-75.

Mills, A. (1986). The acquisition of gender. Berlin: Springer-Verlag.

Morgan, J. L., \& Wheeldon, L. R. (2003). Syllable monitoring in internally and externally generated English words. Journal of Psycholinguistic Research, 32, 269-296.

Muller-Gass, A., Gonthier, I., Desrochers, A., \& Campbell, K. B. (2000). Multiple P3 evidence of a two-stage process in word gender decision. NeuroReport, 16, 3527-3531.

Müller, O., \& Hagoort, P. (2001). Semantic and syntactic properties of a word - Which are first in reading? Abstracts of the Eighth Annual Meeting of the Cognitive Neuroscience Society (p. 124). New York: Cognitive Neuroscience Society.

Näätänen, R. (1982). Processing negativity: An evoked-potential reflection of selective attention. Psychological Bulletin, 92, 605-640.

Näätänen, R. (1992). Attention and brain function. Hillsdale, NJ: Lawrence Erlbaum.

Norris, D., McQueen, J. M., \& Cutler, A. (2000). Merging information in speech recognition: Feedback is never necessary. Brain and Behavioral Sciences, 23, 299-325.

Perfetti, C. A., \& Bell, L. C. (1991). Phonemic activation during the first $40 \mathrm{~ms}$ of word identification: Evidence from backward masking and priming. Journal of Memory and Language, 30, 473-485.

Perfetti, C. A., Bell, L. C., \& Delaney, S. M. (1988). Automatic (prelexical) phonetic activation in silent word reading: Evidence from backward masking. Journal of Memory and Language, 27, $59-70$.

Pfefferbaum, A., Ford, J. M., Weller, B. J., \& Kopell, B. S. (1985). ERPs to response production and inhibition. Electroencephalography and Clinical Neurophysiology, 60, 423-434.

Rodriguez-Fornells, A., Schmitt, B. M., Kutas, M., \& Münte, T. F. (2002). Electrophysiological estimates of the time course of semantic and phonological encoding during listening and naming. Neuropsychologia, 40, 778-787.

Sasaki, K., \& Gemba, H. (1993). Prefrontal cortex in the organization and control of voluntary movement. In T. Ono, L. R. Squire, M. E. Raichle, D. I. Perret, \& M. Fukuda (Eds.), Brain mechanisms of perception and memory: From neuro to behavior (pp. 473-496). New York: Oxford University Press.
Sasaki, K., Gemba, H., Nambu, A., \& Matsuzaki, R. (1993). No-go activity in the frontal association cortex of human subjects. Neuroscience Research, 18, 249-252.

Sasaki, K., Gemba, H., \& Tsujimoto, T. (1989). Suppression of visually initiated hand movement by stimulation of the prefrontal cortex in the monkey. Brain Research, 495, 100-107.

Schiller, N. O. (2002). The incremental nature of phonological encoding in speech production. Manuscript in preparation.

Schiller, N. O., Bles, M., \& Jansma, B. M. (in press). Tracking the time course of phonological encoding in speech production: An eventrelated brain potential study on internal monitoring. Cognitive Brain Research.

Schiller, N. O., \& Caramazza, A. (2003). Grammatical feature selection in noun phrase production: Evidence from German and Dutch. Journal of Memory and Language, 48, 169-194.

Schiller, N. O., Jansma, B. M., Peters, J., \& Levelt, W. J. M. (2002). Phonological encoding of stress: The time course of metrical encoding in polysyllabic words. Manuscript submitted for publication.

Schmitt, B. M., Münte, T. F., \& Kutas, M. (2000). Electrophysiological estimates of the time course of semantic and phonological encoding during implicit picture naming. Psychophysiology, 37, 473-484.

Schmitt, B. M., Rodriguez-Fornells, A., Kutas, M., \& Münte, T. F. (2001). Electrophysiological estimates of semantic and syntactic information access during tacit picture naming and listening to words. Neuroscience Research, 41, 293-298.

Schmitt, B. M., Schiltz, K., Zaake, W., Kutas, M., \& Münte, T. F. (2001). An electrophysiological analysis of the time course of conceptual and syntactic encoding during tacit picture naming. Journal of Cognitive Neuroscience, 13, 510-522.

Schriefers, H., Meyer, A. S., \& Levelt, W. J. M. (1990). Exploring the time course of lexical access in language-production: Pictureword interference studies. Journal of Memory and Language, 29, 86-102.

Schwichtenberg, B., \& Schiller, N. O. (in press). Semantic gender assignment regularities in German. Brain and Language.

Simson, R., Vaughan, H. G., \& Ritter, W. (1977). The scalp topography of potentials in auditory and visual go/nogo tasks. Electroencephalography and Clinical Neurophysiology, 43, 864-875.

Thorpe, S., Fize, D., \& Marlot, C. (1996). Speed of processing in the human visual system. Nature, 381, 520-522.

Tucker, G. R., Lambert, W. E., \& Rigault, A. A. (1977). The French speaker's skill with grammatical gender: An example of rule-governed behavior. The Hague: Mouton.

Van Turennout, M., Hagoort, P., \& Brown, C. M. (1997). Electrophysiological evidence on the time course of semantic and phonological processes in speech production. Journal of Experimental Psychology: Learning, Memory, and Cognition, 23, 787-806.

Van Turennout, M., Hagoort, P., \& Brown, C. M. (1998). Brain activity during speaking: From syntax to phonology in 40 milliseconds. Science, 280, 572-574.

Vigliocco, G., \& Franck, J. (1999). When sex and gender go hand in hand: Gender agreement in language production. Journal of Memory and Language, 40, 455-478.

Vigliocco, G., \& Franck, J. (2001). When sex affects syntax: Contextual influences in sentence production. Journal of Memory and Language, $45,368-390$.

Wheeldon, L., \& Levelt, W. J. M. (1995). Monitoring the time course of phonological encoding. Journal of Memory and Language, 34, 311 334.

Wheeldon, L., \& Morgan, J. L. (2002). Phoneme monitoring in internal and external speech. Language and Cognitive Processes, 17, 503-535.

(Received August 5, 2002; AcCePted April 22, 2003) 
APPENDIX

Phonological Rules (Regularities) of Gender Assignment in German
(1) $/ \mathrm{kn}_{-} /$
(2) $/ \mathrm{S}+\mathrm{C}_{-}$
(3) $/ \mathrm{d}, \mathrm{t}+\mathrm{r}$
(4) $/[m, n, \bar{\eta}+C /$
(5) $/ \mathrm{CC}_{-} \mathrm{CC} /$
(6) /_(C) $+\mathrm{f}, \mathrm{c}, \boldsymbol{\chi}, \boldsymbol{t}$ t/
(7) /_u:r/
(8) /_u:t/
(9) /_i:/
(10) /_a/

\author{
$\rightarrow$ masculine (e.g., Knochen 'bone') \\ $\rightarrow$ masculine (e.g., Stiel 'stalk') \\ $\rightarrow$ masculine (e.g., Trohn 'throne') \\ $\rightarrow$ masculine (e.g., Bund 'alliance') \\ $\rightarrow$ masculine (e.g., Platz 'place') \\ $\rightarrow$ feminine (e.g., Haft 'custody') \\ $\rightarrow$ feminine (e.g., Kultur 'culture') \\ $\rightarrow$ feminine (e.g., Armut 'poverty') \\ $\rightarrow$ feminine (e.g., Ironie 'irony') \\ $\rightarrow$ feminine (e.g., Silbe 'syllable')
}

Note that there are exceptions for all rules (see Köpcke \& Zubin, 1984; Mills, 1986). "C" stands for any consonant. Beside these rules, there are some more gender-marking phonological regularities. For instance, long vowels as well as the suffix -er are markers of nonfeminine gender (e.g., Bad 'bath' or Acker 'field'). Also, rules that apply only to smaller portions of the lexicon are not listed.

Rules (1), (2), (3), (4), and (6) mainly hold for monosyllables. Rule (5) is also called Konsonantenhäufungsprinzip (consonant accumulation principle). It is part of rules (1) to (4). A formal criterion for this principle could be the consonant (C) to vowel (V) ratio. If this ratio is at least three per syllable, we argue that (5) is at play. 